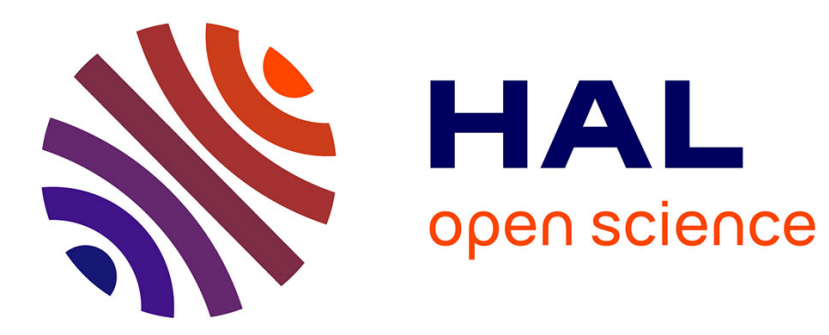

\title{
Non-linear target adjustment in corporate liquidity management: an endogenous thresholds approach
}

\author{
Allard Bruinshoofd, Clemens J.M. Kool
}

\section{To cite this version:}

Allard Bruinshoofd, Clemens J.M. Kool. Non-linear target adjustment in corporate liquidity management: an endogenous thresholds approach. Applied Economics, 2009, 41 (17), pp.2125-2131. 10.1080/00036840701222587 . hal-00582123

\section{HAL Id: hal-00582123 \\ https://hal.science/hal-00582123}

Submitted on 1 Apr 2011

HAL is a multi-disciplinary open access archive for the deposit and dissemination of scientific research documents, whether they are published or not. The documents may come from teaching and research institutions in France or abroad, or from public or private research centers.
L'archive ouverte pluridisciplinaire HAL, est destinée au dépôt et à la diffusion de documents scientifiques de niveau recherche, publiés ou non, émanant des établissements d'enseignement et de recherche français ou étrangers, des laboratoires publics ou privés. 


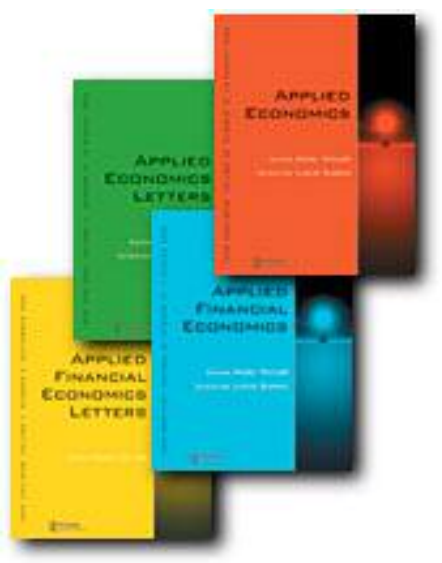

\section{Non-linear target adjustment in corporate liquidity management: an endogenous thresholds approach}

\begin{tabular}{|r|l|}
\hline Journal: & Applied Economics \\
\hline Manuscript ID: & APE-06-0273.R1 \\
\hline Journal Selection: & Applied Economics \\
\hline Aute Submitted by the & 15-Jan-2007 \\
\hline Complete List of Authors: & $\begin{array}{l}\text { Bruinshoofd, Allard; De Nederlandsche Bank, Economics and } \\
\text { Research Division } \\
\text { Kool, Clemens; University of Utrecht, Utrecht School of Economics }\end{array}$ \\
\hline JEL Code: & $\begin{array}{l}\text { C33 - Models with Panel Data < C3 - Econometric Methods: } \\
\text { Multiple/Simultaneous Equation Models < C - Mathematical and } \\
\text { Quantitative Methods, E41 - Demand for Money < E4 - Money and } \\
\text { Interest Rates < E - Macroeconomics and Monetary Economics, G30 } \\
- \text { General < G3 - Corporate Finance and Governance < G - Financial } \\
\text { Economics }\end{array}$ \\
\hline Keywords: & $\begin{array}{l}\text { corporate liquidity management, non-linear adjustment, } \\
\text { endogenous thresholds, panel approach }\end{array}$ \\
\hline
\end{tabular}

\section{\$) ScholarONE" \\ Manuscript Central}




\title{
Non-linear target adjustment in corporate liquidity management:
}

\section{an endogenous thresholds approach ${ }^{1}$}

\author{
W. Allard Bruinshoofd ${ }^{\mathrm{a}}$, Clemens J. M. Kool ${ }^{\mathrm{b}}$
}

${ }^{\text {a }}$ De Nederlandsche Bank - Economics and Research Division, P.O. Box 98, 1000 AB

\author{
Amsterdam, The Netherlands. E-mail Address: w.a.bruinshoofd@dnb.nl \\ ${ }^{\mathrm{b}}$ University of Utrecht - Utrecht School of Economics, Janskerkhof 12, 3512 BL Utrecht, The \\ Netherlands. E-mail Address: c.kool@econ.uu.nl
}

January 2007

\begin{abstract}
We provide new empirical evidence on non-linear liquidity management in Dutch firms. Our results reveal that liquidity adjustment from below the target is significantly faster than from above. We find no evidence for bands of inaction around the target.
\end{abstract}

Keywords: Corporate liquidity management; Non-linear adjustment; Endogenous thresholds; Panel approach

JEL Classifications: C33; E41; G3

\footnotetext{
${ }^{1}$ We thank Jaap Bos, Bertrand Candelon, Leo de Haan, Alain Hecq, Wilko Letterie, Michiel van Leuvensteijn, Jean-Pierre Urbain, Tom van Veen, an anonymous referee, as well as participants of the CAED 1999, the NAKE Research Day 1999, the European Monetary Forum 2002, the Maastricht University Economics Lustrum Conference 2004 and seminar participants at De Nederlandsche Bank for helpful comments. The research is supported by a grant from the Maastricht Research School of Economics of Technology and Organizations (METEOR) and was partially carried out at the Center for Research of Economic Micro-data (Cerem) of Statistics Netherlands. The views expressed are those of the individual authors and do not necessarily reflect official positions of Statistics Netherlands or De Nederlandsche Bank.
} 


\section{Introduction}

While there is by now considerable empirical evidence to support the existence of optimal target levels for long-run corporate liquidity holdings (e.g. Kim et al., 1998; Opler et al., 1999; Ozkan and Ozkan, 2004; Bruinshoofd and Kool, 2004), little evidence exists on possible non-linearities in the speed of adjustment towards these targets. This is particularly surprising since such non-linearities - motivated by liquidity or financing constraints - play an important role in the related corporate investment literature (e.g. Ono, 2003; Pratap, 2003). Obviously, such arguments should straightforwardly extend to the cash management literature.

Opler et al. (1999) theoretically demonstrate that the respective shapes of the marginal cost and benefit curves of liquidity holdings in combination with the structure of adjustment costs determine the speed of corporate liquidity adjustment. In their view, target adjustment from below may be faster than from above, due to a flat marginal cost of liquidity curve and a convex marginal benefit curve. At the same time, their setup supports the hypothesis that adjustment speed rises with the size of target deviations, especially on the lower side. Milne and Robertson (1996) and Pratap (2003) provide a theoretical argument for the case where firms are significantly below target, which is based on increasing risk aversion when threatened by liquidation. On the other hand, Myers and Rajan (1998) provide an argument for quick run-downs of too high liquidity because creditors may dislike overly liquid debtors. Bar-Ilan et al. (2004) argue that fixed adjustment costs may lead to non-monotonous adjustment through bands of inactivity around the target. Indirect adjustment costs may also arise, because funds directed to the stock of liquid assets cannot be used as a source of funds elsewhere in the firm. Ozkan and Ozkan (2004) discuss the consequences of liquidity adjustment for the level of dividend payments, while Almeida et al. (2004) focus on the 
consequences for future investment opportunities. To the best of our knowledge Almeida et al. (2004) are the only ones to explicitly test such non-linearities empirically. They split their sample of firms into a liquidity-constrained part and an unconstrained part. Liquidity dynamics of constrained firms are shown to differ from unconstrained firms.

The present paper significantly extends this literature through its empirical focus on non-linear corporate liquidity adjustment towards long-run targets. ${ }^{2}$ We apply an innovative endogenous threshold regression model to a balanced panel of 450 Dutch non-financial firms for the period 1986-1997. ${ }^{3}$ Table 1 describes the variables used in the analysis. We refer to the table for the definition of the variables.

Table 1

Descriptive statistics

\begin{tabular}{lrrrrrrr}
\hline Variable & \# Obs. & \multicolumn{7}{c}{ Percentiles } & Standard \\
\cline { 3 - 7 } & & \multicolumn{1}{c}{10} & \multicolumn{1}{c}{5} & \multicolumn{1}{c}{5} & \multicolumn{1}{l}{75} & \multicolumn{1}{c}{90} & deviation \\
Liquidity ratio (\%) & 5400 & 0.21 & 0.89 & 4.45 & 15.90 & 37.02 & 28.77 \\
Liquidity & 5400 & -6.14 & -4.72 & -3.11 & -1.84 & -0.99 & 2.08 \\
$\Delta$ Liquidity & 4950 & -1.50 & -0.60 & -0.01 & 0.51 & 1.35 & 1.35 \\
Return on assets & 5400 & -0.00 & 0.02 & 0.05 & 0.10 & 0.15 & 0.10 \\
$\Delta$ Return on assets & 4950 & -0.06 & -0.02 & 0.00 & 0.02 & 0.06 & 0.10 \\
Size & 5400 & 10.44 & 10.83 & 11.52 & 12.51 & 13.78 & 1.34 \\
$\Delta$ Size & 4950 & -0.14 & -0.06 & 0.03 & 0.12 & 0.23 & 0.20 \\
Interest rate & 5400 & 0.00 & 0.02 & 0.04 & 0.06 & 0.10 & 0.12 \\
$\Delta$ Interest rate & 4950 & -0.03 & -0.01 & -0.00 & 0.01 & 0.03 & 0.09 \\
\hline
\end{tabular}

Notes: liquidity ratio (\%) is cash and marketable securities over net assets. Liquidity is the logarithm of cash and marketable securities over net assets and $\Delta$ is the first-difference operator. Return on assets is earnings after depreciation, interest, taxes and extraordinary gains and losses, but before dividend payments to net assets; Size is the logarithm of net assets expressed in 1990 prices; Interest rate is interest expenses as a fraction of total debt, excluding debts to subsidiary companies.

\footnotetext{
${ }^{2}$ Se for example Huang et al. (2001) for an application of a similar conceptual framework in the case of macroeconomic money demand.

${ }^{3}$ We refer to the appendix for details on sample selection.
} 


\section{Estimating conditional adjustment with endogenous thresholds}

In this section, we first provide a definition of long-run firm-specific liquidity targets. In the motivation of this target definition and the discussion of the relation between the target and long-run determinants of corporate liquidity, we extensively draw on Bruinshoofd and Kool (2004), which we henceforth refer to as BK04. Subsequently, we introduce a sophisticated threshold estimation method, developed in Hansen (1999). The advantage of this method is that it allows for endogenous thresholds in a non-dynamic panel. However, using it requires a two step approach where estimated deviations from long-term targets are inputs in the second stage of threshold determination. In our view, the advantages are sufficiently strong to favor this approach over, for instance, a one-step VECM. Section 3 contains the empirical results of our analysis of conditional target adjustment in corporate liquidity holdings,

\section{Computing Firm-level Corporate Liquidity Targets}

In BK04, we start the search for long-run corporate liquidity targets using equation (1).

$$
y_{i t}=\beta_{n}^{\prime} x_{i t}+\eta_{i}+v_{i t}
$$

where liquidity (y) is regressed on determinants $x_{i t}$ while $\eta_{i}$ and $v_{i t}$ denote firm-specific effects and a white noise error term, respectively. Note that subscript $i$ denotes firm $i$, while subscript $t$ denotes time. The vector $x_{i t}$ includes a constant, time and sector dummies and the potential long-run determinants size, near liquidity, total debt, short debt, average interest rate, earnings uncertainty and return on assets while $\beta$ denotes the vector of corresponding parameter estimates. ${ }^{4}$ With respect to the sector dummies, we distinguish three different

\footnotetext{
${ }^{4}$ For a more extensive definition and motivation of this list of long-run determinants, we refer to BK04 and
} 
specifications of equation (1) from high to low aggregation: i) no sector dummies, ii) sector dummies at the 1-digit level, and iii) sector dummies at the 2-digit level.

Based on panel estimation of equation (1), we distinguish twodifferent types of targets in BK04. First, we define 'sophisticated' liquidity targets as the predicted values from the estimated equation (1), $\hat{y}_{i t}^{\text {sophisticated }}=\hat{\beta}^{\prime} x_{i t}$. Since this target definition excludes the firm-specific fixed effect $\left(\hat{\eta}_{i}\right)$, it may inappropriately ignore unobserved heterogeneity in long-run firmlevel liquidity levels. Therefore, we alternatively introduce a second target measure, the socalled 'specific' target, as $\hat{y}_{i t}^{\text {specific }}=\hat{y}_{i t}^{\text {sophisticated }}+\hat{\eta}_{i}=\hat{\beta}^{\prime} x_{i t}+\hat{\eta}_{i} \cdot{ }^{5}$ The evidence in BK04 convincingly demonstrates that unobserved firm-specific heterogeneity plays a dominant role in long-run corporate liquidity levels. We therefore conclude in BK04 that firm-specific effects need to be included in the target definition. ${ }^{6}$ If done so, we find mean reversion to the 'specific' target to equal 68 percent in one year.

In the current paper, we build on the conclusions in BK04 and use firm-specific targets in our analysis. To keep our panel balanced, we define the liquidity target straightforwardly as the historical average liquidity ratio for each firm individually. ${ }^{7}$ In table 2 , we provide simple error-correction estimations for corporate liquidity adjustment on the basis of this target definition, using the following specification - identical to the one used in BK04:

$$
\Delta y_{i t}=\alpha_{i}+\beta^{\text {Controls }_{i t}}+\gamma \text { Deviation }_{i(t-1)}+\varepsilon_{i t} .
$$

\footnotetext{
Opler et al. (1999). Originally, net working capital and investment were included in the list of long-run determinants as well. However, they lacked statistical significance in the long-run equation and were subsequently dropped from the analysis.

${ }^{5}$ Note the resemblance of our approach with the way that debt targets have been computed in the capital structure literature (e.g. Auerbach 1985, Shyam-Sunder and Myers 1999 and Drobetz and Wanzenried 2006).

${ }^{6}$ This conclusion is independent of the level of aggregation of the included sector dummies; that is, even 2-digit sector dummies do not adequately capture individual firm's idiosyncratic long-run liquidity levels.

${ }^{7}$ The motivation for this simplification is that the endogenous threshold method applied later on is tailored to balanced panels and it is unsure whether its asymptotic properties extend to unbalanced panels. At the same time, the dominance of the firm-specific effects in the cross-sectional variation of liquidity targets limits the resulting loss in precision.
} 


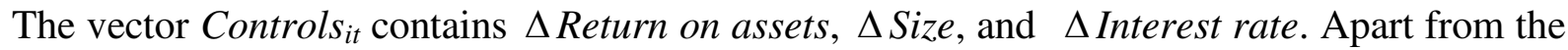
baseline estimation, we also present in table 2 a number of extensions in terms of specification and estimation method to assess the appropriateness and robustness of our results.

Table 2

Modeling corporate liquidity adjustment

\begin{tabular}{lccccc}
\hline & OLS & $\begin{array}{c}\text { Fixed } \\
\text { effects }\end{array}$ & FGLS & OLS & OLS \\
\hline Deviation $_{\mathrm{i}, \mathrm{t}-1}$ & -0.613 & -0.605 & -0.601 & -0.635 & -0.622 \\
& $(0.021)$ & $(0.022)$ & $(0.013)$ & $(0.025)$ & $(0.021)$ \\
$\Delta$ Return on assets $_{\mathrm{i}, \mathrm{t}}$ & 0.995 & 0.979 & 0.867 & 0.988 & 0.970 \\
& $(0.310)$ & $(0.316)$ & $(0.111)$ & $(0.392)$ & $(0.303)$ \\
$\Delta$ Size $_{\mathrm{i}, \mathrm{t}}$ & -1.031 & -1.111 & -1.007 & -1.041 & -1.068 \\
& $(0.093)$ & $(0.101)$ & $(0.049)$ & $(0.097)$ & $(0.095)$ \\
$\Delta$ Interest rate $_{\mathrm{i}, \mathrm{t}}$ & -0.335 & -0.337 & -0.138 & -0.308 & -0.354 \\
& $(0.257)$ & $(0.277)$ & $(0.129)$ & $(0.258)$ & $(0.260)$ \\
$\Delta$ Liquidity $_{\mathrm{i},-1}$ & - & - & - & 0.009 & - \\
& & & & $(0.022)$ & NO \\
Constant term & YES & YES & YES & YES & YES \\
Fixed time effects & NO & NO & NO & NO & \\
& & & & & 4983 \\
\# observations & 4983 & 4983 & 4983 & 4983 & 0.36 \\
R-squared & 0.35 & 0.35 & 0.33 & 0.35 & \\
F-test 'no fixed effects' & & 0.22 & & & \\
Hausman test & & & 2.52 & & \\
Common AR(1) coefficient & & & 0.06 & & \\
\hline
\end{tabular}

Notes: dependent variable is $\Delta y$ ( $\Delta$ Liquidity); robust standard errors are in parentheses. FGLS estimates assume a heterogeneous panel with an $\mathrm{AR}(1)$ process in the error term that is common to all firms. ${ }^{*}$ and ${ }^{* *}$ denote significance at the $5 \%$ and $1 \%$ error level, respectively.

The first column with estimation results in table 2 presents our benchmark OLS estimation with robust standard errors. The mean reversion coefficient $(-0.61)$ is close to the value found in BK04 where a more sophisticated firm-specific target was used. Also the coefficients on the control variables are qualitatively similar in size and significance to those in BK04. Only for the change in the interest rate, we now find an insignificant effect, as opposed to BK04. 
Overall, the estimation result provides support for our use of a simple firm-specific historical average as target.

Subsequently, we introduce firm fixed effects in the mean-reversion analysis. The coefficients in the next column are virtually the same as for the benchmark OLS case. The Ftest that firm-specific effects are absent cannot be rejected. In the subsequent column we use FGLS to test for the combined presence of heteroskedasticity and autocorrelation, as these may affect the consistency and efficiency of the estimated parameters. Size and significance of the estimated parameters is very robust against this extension. Moreover, the Hausman test statistic suggests that this set of coefficients is statistically identical to the fixed effect estimates. Note also that the estimated autocorrelation coefficient is rather small and statistically insignificantly different from zero. Additionally allowing for cross-sectional correlation leads to over-identification of the model, although the parameter estimate of lagged target deviation (-0.697 with a standard error of 0.073$)$ remains broadly in line with the benchmark OLS case. The final two columns of table 2 show extensions of the baseline OLS model to allow for persistence in liquidity dynamics and to capture fixed time effects. Again, neither one of these extensions significantly influences our results. The dynamic model includes the one-year lagged change in liquidity as an additional variable. Here, we use the fact that we failed to find statistical support for firm-fixed effects and do not need to resort to Arellano-Bond type estimators for the dynamic model. We conclude that lagged liquidity dynamics have no material impact in the equation and its inclusion does not affect the other parameter estimates. This finding is crucial for the next step in our analysis as the underlying assumptions of the Hansen method forbid the use of lags of the dependent variable among the explanatory variables. Our finding in table 2 thus warrants the use of the Hansen method in this respect. 


\section{The endogenous threshold method}

Hansen (1999) develops a sophisticated non-dynamic panel approach to estimate threshold effects. To apply his method to the case of corporate liquidity adjustment, we slightly adjust our formulation of liquidity dynamics from equation (2) into:

$$
\begin{aligned}
\Delta y_{i t}= & \alpha_{i}+\beta \text { Control }_{i t}+\gamma_{1} \text { Deviation }_{i(t-1)} I_{1}\left(\text { Deviation }_{i(t-1)} \leq \varphi\right) \\
& +\gamma_{2} \text { Deviation }_{i(t-1)} I_{2}\left(\text { Deviation }_{i(t-1)}>\varphi\right)+\varepsilon_{i t}
\end{aligned},
$$

where Controls $_{i t}$ and $\beta^{\prime}$ again represent the vectors of control variables and corresponding

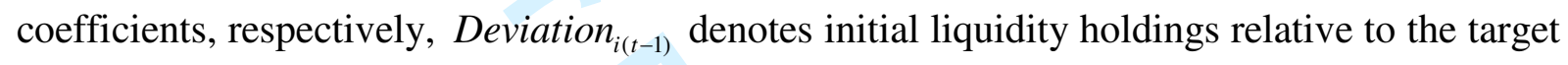
level, $\alpha_{i}$ denotes firm-specific intercepts, and $\varepsilon_{i t}$ is an iid error term. Our focus is on the conditional adjustment speed $\gamma_{j}$, which depends on the indicator function $I_{j}$. The indicator $I_{j}$ partitions the data using the - unobservable - threshold $\varphi$. For any given $\varphi$ the slope coefficients can be estimated by OLS, as evidenced by the experiments in table 2 . Let $\varphi_{0}$ be the true threshold value and $\hat{\varphi}$ its least squares estimate. The least squares estimate is obtained where the value of the error sum of squares (ESS) is minimized:

$$
\hat{\varphi}=\underset{\varphi}{\arg \min } \operatorname{ESS}(\varphi)
$$

As $\operatorname{ESS}(\varphi)$ depends on $\varphi$ only through the indicator functions $I_{j}($.$) it is a step function with$ at most $n T$ steps, where $n$ is the number of firms and $T$ the number of years per firm in the data. To reduce the number of regressions involved, a grid search for values of $\varphi$ corresponding to the quantiles of Deviation $_{i(t-1)}$ is applied, using the quantiles $\{1.00 \%, 1.25 \%$, $1.50 \%, \ldots, 89.50 \%, 89.75 \%, 99.00 \%\}$ 
Two issues of inference should be addressed. First, we need to determine the statistical significance of the threshold effect, i.e. evaluate the hypothesis $H_{0}: \gamma_{1}=\gamma_{2}$. Since $\varphi$ is not identified under the null, we use bootstrapping to simulate the asymptotic distribution of the likelihood ratio test. P-values constructed from the bootstrap are asymptotically valid for $n \rightarrow \infty$, a condition satisfied in our data where $n$ equals 450 (firms). ${ }^{8}$ Second, we need a measure of precision of our estimate of $\varphi_{0}$. As $\hat{\varphi}$ is a consistent estimate of $\varphi_{0}$, for each $\varphi$ evaluated in the grid search we may evaluate $H_{0}: \varphi=\hat{\varphi}$. Confidence intervals are defined as a 'no rejection region' using the likelihood ratio statistic for tests on $\varphi(L R(\varphi))$. A test of $H_{0}: \varphi=\hat{\varphi}$ rejects at the asymptotic level $\alpha$ if $L R(\varphi)$ exceeds the critical value $c(\alpha)$. Hence the 'no rejection region' of confidence level $1-\alpha$ is the set of $\varphi$ such that $L R(\varphi) \leq c(\alpha)$. Note that $L R(\varphi)$ is a re-normalization of the error sum of squares for each value of $\varphi$ and therefore a by-product of model estimation. The method extends in a natural manner to models with multiple thresholds. We refer to Hansen (1999) for technical details.

\section{Results}

We now turn to the joint estimation of thresholds levels and regression coefficients as formulated in equation (3). Table 3 contains the results.

Panel A presents formal threshold effects test results, which suggest a triple threshold model. ${ }^{9}$ Panel $\mathrm{B}$ of the table reports the threshold estimates themselves along with $95 \%$ confidence bands. Here we see that the middle threshold is positive but insignificantly

\footnotetext{
${ }^{8}$ Since the likelihood ratio test statistic may not be asymptotically pivotal, a word of caution on the efficiency of the bootstrapped test statistic is warranted. The errors of bootstrap estimates of the distribution of statistics that are not asymptotically pivotal converge to zero at the same rate as the errors made by first-order asymptotic approximations (see Horowitz, 2001).

${ }^{9}$ Additionally, Shapiro-Francia W' tests for normality of the residuals of the triple-threshold model reveal that at the $99 \%$ confidence level normality is accepted for more than $90 \%$ of the firms in our sample.
} 
Table 3

Threshold effects, threshold estimates, and regression results

\begin{tabular}{|c|c|c|}
\hline \multicolumn{3}{|l|}{ PANEL A: Test statistics for threshold effects } \\
\hline Single threshold (P-value) & 41.6 & $(0.00)$ \\
\hline Double threshold (P-value) & 16.2 & $(0.00)$ \\
\hline Triple threshold (P-value) & 13.7 & $(0.01)$ \\
\hline \multicolumn{3}{|l|}{ PANEL B: Threshold estimates } \\
\hline$\hat{\varphi}_{1}(95 \%$ confidence interval $)$ & -2.86 & $(-3.03 ;-2.73)$ \\
\hline$\hat{\varphi}_{2}(95 \%$ confidence interval $)$ & 0.85 & $(-0.58 ; 1.50)$ \\
\hline$\hat{\varphi}_{3}(95 \%$ confidence interval $)$ & 3.05 & $(2.86 ; 3.05)$ \\
\hline \multicolumn{3}{|l|}{ PANEL C: Regression results ${ }^{\text {a) }}$} \\
\hline$\Delta$ Return on assets ${ }_{i, t}$ & 0.71 & $(0.36)$ \\
\hline$\Delta$ Size $_{\mathrm{i}, \mathrm{t}}$ & -1.20 & $(0.11)$ \\
\hline$\Delta$ Interest rate $_{i, t}$ & -0.36 & $(0.26)$ \\
\hline Deviation $_{\mathrm{i}, \mathrm{t}-1} \times \mathrm{I}\left(\right.$ Deviation $\left._{\mathrm{i}, \mathrm{t}-1} \leq \hat{\varphi}_{1}\right)$ & -0.87 & $(0.06)$ \\
\hline Deviation $_{\mathrm{i}, \mathrm{t}-1} \times \mathrm{I}\left(\hat{\varphi}_{1}<\right.$ Deviation $\left._{\mathrm{i}, \mathrm{t}-1} \leq \hat{\varphi}_{2}\right)$ & -0.68 & $(0.03)$ \\
\hline Deviation $_{\mathrm{i}, \mathrm{t}-1} \times \mathrm{I}\left(\hat{\varphi}_{2}<\right.$ Deviation $\left._{\mathrm{i}, \mathrm{t}-1} \leq \hat{\varphi}_{3}\right)$ & -0.45 & $(0.04)$ \\
\hline Deviation $_{\mathrm{i}, \mathrm{t}-1} \times \mathrm{I}\left(\hat{\varphi}_{3}<\right.$ Deviation $\left._{\mathrm{i}, \mathrm{t}-1}\right)$ & -0.66 & $(0.10)$ \\
\hline Firm-specific intercepts & YES & \\
\hline
\end{tabular}

different from zero. Unreported results show that our estimates are only marginally affected by restricting the second threshold to equal zero. For the remainder of the discussion we shall therefore interpret the second threshold as being zero. The first and third threshold estimates are particularly low and high, corresponding with liquidity shortfalls of more than $95 \%$ below the target and liquidity surpluses of over $2000 \%$ above the target, respectively. Although the third threshold effect is statistically significant, the regime above the third threshold contains only about 50 observations and the estimated threshold estimate is implausibly high. We check the robustness of this threshold by alternately winsorizing and censoring the data. We winsorize our data by removing firms from the sample in such a way that a minimum number of firms is deleted while a maximum number of extreme target deviations is removed from the 
sample. ${ }^{10}$ We censor our data by replacing the deviations of the top and bottom $1 \%$ of the deviations distribution with the $99^{\text {th }}$ and the $1^{\text {st }}$ quantile values, respectively. ${ }^{11}$ The results of these sensitivity checks - presented in table 4 - show that in either case the third threshold effect loses statistical significance, while the other thresholds effects as well as the regression coefficients remain broadly unchanged.

Table 4

Estimation results using winsorized and censored data

\begin{tabular}{|c|c|c|c|c|}
\hline re & Winsor & $\begin{array}{l}\text { zed, uncensored } \\
\text { sample }\end{array}$ & & $\begin{array}{l}\text { 1, censored } \\
\text { Sample }\end{array}$ \\
\hline \multicolumn{5}{|c|}{ PANEL A: Test statistics for threshold effects } \\
\hline Single threshold (P-value) & 55.0 & $(0.00)$ & 67.0 & $(0.00)$ \\
\hline Double threshold (P-value) & 16.3 & $(0.01)$ & 12.9 & $(0.04)$ \\
\hline Triple threshold (P-value) & 6.4 & $(0.33)$ & 7.8 & $(0.15)$ \\
\hline \multicolumn{5}{|l|}{ PANEL B: Threshold estimates } \\
\hline$\hat{\varphi}_{1}(95 \%$ confidence interval $)$ & -2.98 & $(-2.99 ;-2.77)$ & -2.99 & $(-2.99 ;-2.99)$ \\
\hline$\hat{\varphi}_{2}(95 \%$ confidence interval $)$ & 0.85 & $(-1.22 ; 1.50)$ & 0.85 & $(-1.72 ; 1.54)$ \\
\hline$\hat{\varphi}_{3}(95 \%$ confidence interval $)$ & - & & - & \\
\hline \multicolumn{5}{|l|}{ PANEL C: Regression results ${ }^{\text {a) }}$} \\
\hline$\Delta$ Return on assets $_{\mathrm{i}, \mathrm{t}}$ & 1.18 & $(0.26)$ & 0.77 & $(0.33)$ \\
\hline$\Delta$ Size $_{\mathrm{i}, \mathrm{t}}$ & -1.16 & $(0.11)$ & -1.21 & $(0.11)$ \\
\hline$\Delta$ Interest rate $_{i, t}$ & -0.22 & $(0.23)$ & -0.33 & $(0.26)$ \\
\hline \multicolumn{5}{|l|}{ Deviation $_{\mathrm{i}, \mathrm{t}-1} \times$} \\
\hline $\mathrm{I}\left(\right.$ Deviation $\left._{\mathrm{i}, \mathrm{t}-1} \leq \hat{\varphi}_{1}\right)$ & -0.95 & $(0.07)$ & -1.00 & $(0.07)$ \\
\hline \multicolumn{5}{|l|}{ Deviation $_{\mathrm{i}, \mathrm{t}-1} \times$} \\
\hline $\mathrm{I}\left(\hat{\varphi}_{1}<\right.$ Deviation $\left._{\mathrm{i}, \mathrm{t}-1} \leq \hat{\varphi}_{2}\right)$ & -0.67 & $(0.03)$ & -0.67 & $(0.03)$ \\
\hline \multicolumn{5}{|l|}{ Deviation $_{\mathrm{i}, \mathrm{t}-1} \times$} \\
\hline $\mathrm{I}\left(\hat{\varphi}_{2}<\right.$ Deviation $\left._{\mathrm{i}, \mathrm{t}-1} \leq \hat{\varphi}_{3}\right)$ & -0.49 & $(0.04)$ & -0.51 & $(0.04)$ \\
\hline \multicolumn{5}{|l|}{ Deviation $_{\mathrm{i}, \mathrm{t}-1} \times$} \\
\hline $\mathrm{I}\left(\hat{\varphi}_{3}<\right.$ Deviation $\left._{\mathrm{i}, \mathrm{t}-1}\right)$ & - & & - & \\
\hline Firm-specific intercepts & YES & & YES & \\
\hline
\end{tabular}

\footnotetext{
${ }^{10}$ The Hansen (1999) methodology is tailored to balanced panels, while it is unsure whether its asymptotic properties extend to unbalanced panels. We therefore aim to keep the panel balanced and remove seventeen firms entirely from the sample rather than unbalancing our panel by removing individual observations.

${ }^{11}$ We have also censored at the $2^{\text {nd }}$ and $98^{\text {th }}$ quantile. This hardly affects the outcomes.
} 
The regression coefficients are in Panel $\mathrm{C}$ of table 2. Regarding the control variables changes in earnings, size and interest rates - we note that the coefficient signs are in line with the literature. Our main finding is that the speed of adjustment towards the target significantly differs across regimes. The differences are not only significant in a statistical sense, but are also economically meaningful. Specifically, our results reveal that firms respond to liquidity shortages considerably faster than they do to liquidity surpluses. Roughly speaking, firms correct liquidity surpluses at a rate of about forty-five percent per year, while they remove liquidity shortages at a rate of nearly seventy percent. For liquidity positions that fall particularly far short of the target $\left(\right.$ Deviation $\left._{i(t-1)} \leq \hat{\varphi}_{1}\right)$, we even find nearly full target adjustment within a year. The latter result, however, may reflect survivorship effects stemming from our use of a balanced panel. Consequently, it may not generalize to other

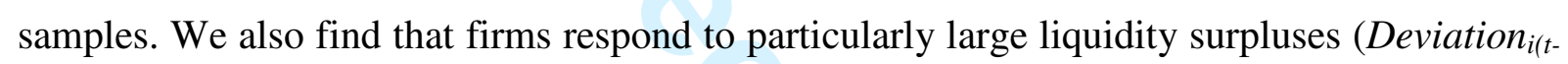
1) $>\hat{\varphi}_{3}$ ) faster than they do to more moderate surpluses. As this third threshold is not robust to either winsorizing or censoring, we caution against strong conclusions from this observation. Lastly, our results do not support the notion of a range of inaction around target liquidity holdings.

\section{Conclusions}

The main finding in this paper is that firms bring back liquidity holdings to targeted levels at a faster rate when they are initially below the target than when they start out above the target. No evidence is found to support the existence of bands of inactivity around the target.

Our results reveal a stronger corporate preference for removing liquidity shortages than for removing liquidity surpluses. In relation to the literature on corporate investment and 
dividend payments, these findings suggests that liquidity shortages are more likely to spill over in the form of curbed investment outlays or cuts to dividend payments than liquidity surpluses are likely to feed additional investment outlays or increases in dividend payments.

\section{References}

Auerbach, A. J., 1985. Real determinants of corporate leverage. In B.M. Friedman, ed., Corporate Capital Structures in the United States, University of Chicago Press.

Almeida, H., Campello, M., Weisbach, M.S., 2004. The Cash Flow Sensitivity of Cash. Journal of Finance 59, 1777-1804.

Bar-Ilan, A., Perry, D., Stadje, W., 2004. A Generalized Impulse Control Model of Cash Management. Journal of Economic Dynamics and Control 28, 1013-1033.

Bruinshoofd, W. A., Kool, C. J. M., 2004. Dutch Corporate Liquidity Management: New Evidence on Aggregation. Journal of Applied Economics 7, 195-230.

Drobetz, W., and G. Wanzenried, 2006. What Determines the Speed of Adjustment to the Target Capital Structure? Applied Financial Economics 16, 941-958.

Hansen, B. E., 1999. Threshold Effects in Non-Dynamic Panels: Estimation, Testing, and Inference. Journal of Econometrics 93, 345-368.

Horowitz, J. L., 2001. The Bootstrap. In J. J. Heckman and E. E. Leamer, eds., Handbook of Econometrics 5, Elsevier.

Huang, C. J., Lin, C. F. J., Cheng, J. C., 2001. Evidence on Nonlinear Error Correction in Money Demand: The Case of Taiwan. Applied Economics 33, 1727-1736.

Kim, C.-S., Mauer, D. C., Sherman, A. E., 1998. The Determinants of Corporate Liquidity: Theory and Evidence. Journal of Financial and Quantitative Analysis 33, 335-359.

Milne, A., Robertson, D., 1996. Firm Behaviour under the Threat of Liquidation. Journal of Economic Dynamics and Control 20, 1427-1449. 
Myers, S. C., Rajan, R. G., 1998. The Paradox of Liquidity. Quarterly Journal of Economics $63,733-771$.

Ono, M., 2003. A Computational Approach to Liquidity-Constrained Firms over an Infinite Horizon. Journal of Economic Dynamics and Control 28, 189-205.

Opler, T., Pinkowitz, L., Stulz, R. M., Williamson, R., 1999. The Determinants and Implications of Corporate Cash Holdings. Journal of Financial Economics 52, 3-46.

Ozkan, A., Ozkan, N., 2004. Corporate Cash Holdings: An Empirical Investigation of UK Companies. Journal of Banking and Finance 28, 2103-2134.

Pratap, S., 2003. Do Adjustment Costs Explain Investment-Cash Flow Insensitivity? Journal of Economic Dynamics and Control 27, 1993-2006.

Shyam-Sunder, L., and S. C. Myers, 1999. Testing static trade off against pecking order models of capital structure. Journal of Financial Economics 51, 219-244.

\section{Appendix. Sample selection}

Our sample is selected from Statistics Netherlands' data on the Finances of Large Firms (SFGO) covering the period 1977-1997. The SFGO provides company specific financial information at the level of balance sheet and income statement items for all Dutch nonfinancial firms with a balance sheet length of at least 20 million Dutch guilders (about EUR 9.1 million). On an annual basis, the data cover 80 to 90 percent of the population.

Occasionally, firms do not report in a given year so that missing data entries arise. In some cases, firms may leave due to financial distress raising the issue of survivorship bias or because they drop below the threshold level of assets. However, in many other cases firms do not leave but simply do not report their financial statements to SFGO in one or more years after which they return. We are unable to distinguish between these different cases. As the 
asymptotic properties of our empirical methodology are known only for balanced panels, we exclude firms with missing data.

In the early years, the number of firms on which Statistics Netherlands reports is quite small. Moreover, data then only cover the manufacturing sector. Data on the services sector start becoming available in 1983 and coverage increases substantially in the first years after. Therefore, we construct our balanced panel starting in 1986. Utilities firms are excluded from the sample and three more firms are removed because they display extreme volatility in liquidity dynamics. At the end of the day we have a balanced panel with 450 firms covering the period 1986-1997. 